A physical exercise program using music-supported video-based training in older adults in nursing homes suffering from dementia: a feasibility study Peer-reviewed author version

SPILDOOREN, Joke; SPEETJENS, Ite; Abrahams, Johan; FEYS, Peter \& TIMMERMANS, Annick (2018) A physical exercise program using music-supported video-based training in older adults in nursing homes suffering from dementia: a feasibility study. In: AGING CLINICAL AND EXPERIMENTAL RESEARCH, 31 (2), pag. 279-285.

DOI: $10.1007 / \mathrm{s} 40520-018-0954-5$

Handle: http://hdl.handle.net/1942/26250 


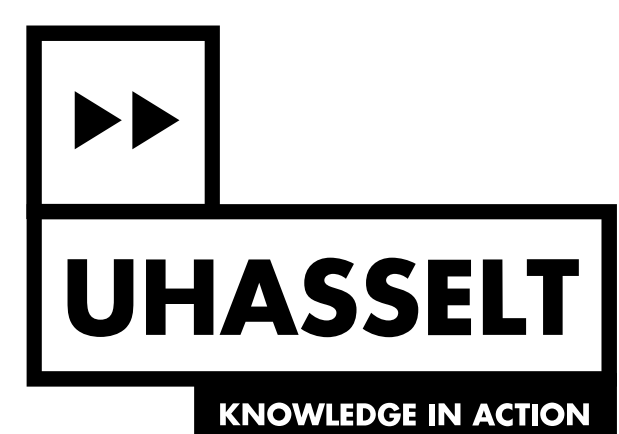

A physical exercise program using music-supported video-based training in older adults in nursing homes suffering from dementia: a feasibility study Link

Peer-reviewed author version

Made available by Hasselt University Library in Document Server@UHasselt

Reference (Published version):

Spildooren, Joke; Speetjens, Ite; Abrahams, Johan; Feys, Peter \& Timmermans, Annick A. (2018) A physical exercise program using music-supported video-based training in older adults in nursing homes suffering from dementia: a feasibility study. In: AGING CLINICAL AND EXPERIMENTAL RESEARCH,

DOI: $10.1007 /$ s40520-018-0954-5

Handle: http://hdl.handle.net/1942/26250 


\section{Aging Clinical and Experimental Research \\ A PHYSICAL EXERCISE PROGRAM USING MUSIC SUPPORTED VIDEO-BASED TRAINING IN OLDER ADULTS IN NURSING HOMES SUFFERING FROM DEMENTIA: A FEASIBILITY STUDY. \\ --Manuscript Draft--}

Manuscript Number:

Full Title:

Article Type:

Funding Information:

Abstract:

Corresponding Author:

Corresponding Author Secondary

Information:

Corresponding Author's Institution:

Universiteit Hasselt

Corresponding Author's Secondary Institution:

First Author:

First Author Secondary Information:

Order of Authors:

Order of Authors Secondary Information:

Author Comments:
ACER-D-18-00028R1

A PHYSICAL EXERCISE PROGRAM USING MUSIC SUPPORTED VIDEO-BASED TRAINING IN OLDER ADULTS IN NURSING HOMES SUFFERING FROM DEMENTIA: A FEASIBILITY STUDY.

Short Communication

Background: Motivation towards an exercise program is higher in a small group setting in comparison to individual therapy. Due to attentional problems, group exercises are difficult for people with Alzheimer disease (AD). This study evaluates the feasibility of a music supported video-based group exercise program in older adults suffering from AD.

Methods: 5 Participants with moderate AD were recruited from a nursing home. A progressive physical exercise program using a video-based training with musical accompaniment was performed and digitally recorded to investigate the adherence and performed accuracy of the exercises.

Results: The overall participation during the exercises was $84.1 \%$. The quality of the performance was for all exercises above the cut-off scores.

Conclusion: A music supported video-based group exercise program is feasible in persons with $A D$. The participants were motivated and the expectations towards the program increased over time. Music seemed an important factor for attention in participants with $A D$.

Joke Spildooren, Ph. D.

Universiteit Hasselt

Diepenbeek, BELGIUM 
translated to English for publication.

Response to Reviewers:

With this feasibility study authors demonstrated that a music supported video-based group exercise program is possible in subjects affected by AD.

The study is of interest; however, I have few concerns requiring a revision before its publication:

1) There are some typographical errors throughout the manuscript.

All the typographical errors are corrected in the manuscript. For example:

pg 5: "invetory" is changed in "inventory"

pg 5: "Bonferri correction" is changed in "Bonferroni correction"

2) Tables need improvement to help interpretation.

Table 1: I have added additional lines between "warming up", "main components" and "cooling down". This clarifies the different components of the exercise program.

Table 2:

- Heading table is changed Baseline characteristics of the participants presented as Mean (SD) and individual values for each participant $(n=5)$.

- vertical lines in the table make a clear discrimination between the mean values and the individual values of each participant.

- GDS and MMSE are now written in capital letters.

Table 3: Converted in graph (See Comment 4)

Table 4: Converted in graph (See Comment 4)

Table 5:

-Horizontal lines make a distinction between the different evaluation scales: "Intrinsic Motivation Inventory (IMI)", "Credibility and Expectancy Questionnaire (CEQ)" and "Observed Emotion Rating Scale (OERS)".

-The subscales of each evaluation are clarified by an interspace and the heading of the evaluation scales are enlarged and written in italics.

-Interquartile range (IQR) is now presented as (Q1-Q3) instead of $(\mathrm{Q} 1 ; \mathrm{Q} 3)$ for a clearer distinction between the decimal sign and the difference between Q1 and Q3.

-Table 5 is now changed into Table 3 as Table 3 and 4 are converted in graphs.

3) Authors should better clarify the strengths and limitations (including the small sample size) of the study.

The following sentences are added in the manuscript: "Some limitations and strengths of the study should be recognized. Only 5 participants were included in this feasibility study. Further, as a result of AD, enthusiasm can differ between and within days, which might have an effect on the quality of each training. To reduce this variable, median values for quality, quantity and emotions were calculated within the same week. This exercise program requires no costly equipment and may therefore be a favorable replacement for many expensive rehabilitation devices. Future research should investigate the added value of the combination of the exercise program with a guiding physical therapist to group therapy solely led by a physical therapist."

4) Tables 3 and 4 can be converted in graphs.

Both tables are now converted in graphs with bars. The results are converted into percentage of maximum repetitions for a clearer overview. 


\title{
A PHYSICAL EXERCISE PROGRAM USING MUSIC SUPPORTED VIDEO-BASED TRAINING IN OLDER ADULTS IN NURSING HOMES SUFFERING FROM DEMENTIA: A FEASIBILITY STUDY.
}

\author{
Spildooren Joke ${ }^{1}, \mathrm{PT}, \mathrm{PhD}$, Speetjens Ite ${ }^{1}, \mathrm{PT}, \mathrm{MSc}$, Abrahams Johan ${ }^{2}, \mathrm{MSc}$, Feys Peter ${ }^{1}, \mathrm{PT}$, \\ $\mathrm{PhD}$, Timmermans Annick ${ }^{1}, \mathrm{PT}, \mathrm{PhD}$.
}

\begin{abstract}
${ }^{1}$ REVAL Rehabilitation Research Center, BIOMED Biomedical Research Institute, Faculty of Medicine and Life Sciences, Hasselt University.

${ }^{2}$ Zorggroep Begralim, Demerstraat 80, 3500 Hasselt, Belgium
\end{abstract}

\section{Corresponding author:}

Joke Spildooren

REVAL Rehabilitation Research Center

BIOMED Biomedical Research Institute

Faculty of Medicine and Life Sciences

Hasselt University.

Agoralaan Building A, Diepenbeek, Belgium

+3211269256

Joke.spildooren@uhasselt.be

Conflicts of interest and Source of Funding: Nothing to declare 


\section{ABSTRACT}

Background: Motivation towards an exercise program is higher in a small group setting in comparison to individual therapy. Due to attentional problems, group exercises are difficult for people with Alzheimer disease (AD). This study evaluates the feasibility of a music supported video-based group exercise program in older adults suffering from AD.

Methods: 5 Participants with moderate AD were recruited from a nursing home. A progressive physical exercise program using a video-based training with musical accompaniment was performed and digitally recorded to investigate the adherence and performed accuracy of the exercises.

Results: The overall participation during the exercises was $84.1 \%$. The quality of the performance was for all exercises above the cut-off scores.

Conclusion: A music supported video-based group exercise program is feasible in persons with AD. The participants were motivated and the expectations towards the program increased over time. Music seemed an important factor for attention in participants with AD.

Key words: Alzheimer Disease, group therapy, video-based exercise, nursing home, music 


\section{INTRODUCTION}

Alzheimer's disease (AD) is characterized by impaired cognitive functions along with motor symptoms such as a reduction in speech and facial expression, tremor, rigidity, posture and gait problems and bradykinesia [1]. All of these symptoms can lead to a reduced independence in performing activities of daily living and reduced quality of life [2] and consequently to the need for permanent institutionalized care [3].

In addition to the administration of medication and the adaptation of nutrition, small group exercise programs have a positive effect on balance and functionality in older adults with $\mathrm{AD}[4]$ and become more attractive in nursing homes due to a shortage of physical therapists. As a result of the social aspect, motivation towards an exercise program is higher in a group setting in comparison to individual therapy in older adults [5]. However, for people with AD, it is hard to focus on the exercises for 30 minutes or longer in group due to attentional problems. Technology-assisted care such as a video prompting program aimed at guiding older adults trough activity steps for table preparation or coffee setting, improved the performance of daily activities in people with AD in comparison to verbal instructions by a physical therapist [6]. Instrumental musical accompaniment during exercises also increases the focus and participation of older people with dementia in a group exercise program [7].

The aim of the present study is to adapt the normal group exercise sessions by replacing the instructions of a physical therapist by exercises demonstrated by an older person on a TVscreen in combination with instrumental tempo related music. Previous study on a supervised music-video exercise program for persons with diabetes showed that the combination of music and video elicits the highest level of attention and exercise enjoyment [8]. The approach of replacing the instructor by video demonstrated exercises can be a way to offer additional physical therapy and creates a more efficient approach in providing therapy in group sessions as the therapist has the ability to correct the performances and overview all participants.

The objective of the study is to evaluate the feasibility and obtained accuracy of a music supported video-based exercise program in older adults suffering from AD.

\section{METHODS}

Study Design And Participants 
The 3-week intervention was conducted in a nursing home with a session frequency of 3 times

\section{Outcome Measures} The inclusion criteria were: institutionalized people aged 80 or older, diagnosis of $\mathrm{AD}$, moderate cognitive impairment as classified by Mini-Mental State Examination (MMSE) scores of 10 to 20 [9] and the ability to walk independently for at least 2 meters with or without a mobility aid. Individuals who were admitted to the nursing home for less than 3 months or had severe hearing- or visual loss such that watching television becomes impossible, were excluded from the study. This study was approved by the leading ethics committee of the Medical department of the of the University of Leuven and the local ethics committee of the Medical department of the Hasselt.

\section{Intervention}

The intervention was performed in a group of 5 participants, supervised by a physical therapist. The therapist had only a supporting role for safety reasons. The participants practiced a video recorded exercise program in the gym room of the nursing home. The exercise program consisted of digitally recorded exercises performed by a 77-year old woman accompanied with instrumental music of the sixties to motivate and encourage participation. The tempo and music genre were selected for each exercise separately to create a calming environment for balance exercises and a stimulating environment for endurance training. At the beginning of the sessions, the participants were asked to imitate the exercises which were displayed on a 54 inch flat screen TV. Concerning the comfort of the participants, chairs with armrests were used. An overview of the exercise program can be found in table 1. The level of difficulty and intensity increased during the exercise program. Each session started with warming-up exercises followed by exercises that target strength (with or without 2 manual weights of 0.5 $\mathrm{kg}$ each), static and dynamic balance (with or without external support of the arms on a mobility aid), functional abilities, endurance and flexibility. 
Adherence was measured as the number of subjects who finished the program, the

Quantity of the participants' performances: All group sessions were videotaped. Based on the digital recording, participants' amount of repetitions of the physical exercise was rated from zero (no repetitions) to three (all repetitions). A score of two was chosen as cut-off score, indicating that more than half of the exercises were performed.

Quality of the participants' performances: The recorded performances were compared with the visual instructions on the TV-screen and were scored on a scale from zero (no repetitions) to three (the performance matched completely with the instructions). A score of two was chosen as cut-off score, indicating that more than half of the exercises were matched with the instructions. Total score at each of the 6 components 'warming-up', 'strength', 'static balance', 'dynamic balance', 'functional exercises', 'endurance' and 'flexibility' consisted of scores on each exercise of that component.

Five subscales (interest/enjoyment, perceived competence, effort/importance, pressure/tension and perceived choice) of the Intrinsic Motivation Inventory (Dutch version) [10] were used to evaluate the degree of motivation and feelings regarding the exercise program. Each subscale is rated from one (not at all true) to seven (very true).

The Credibility Expectancy Questionnaire [11], assesses the credibility of the intervention and the expectancy of the participants towards positive effects of the program.

The emotions (pleasure, interest/alertness, anger, anxiety, sadness) of the participants are observed from the digital recordings during the 5 minutes at the beginning and end of the training session using the Observed Emotion Rating Scale (OERS) [12].

\section{Statistical Analyses}

Data are presented as percentage (for adherence, quantity and quality) or median value and interquartile range (for intrinsic motivation inventory, credibility and OERS) calculated over the 3 sessions within the same week.

Statistical comparison over time is performed using a Friedman two-way analysis of variance by ranks $(\alpha=.05)$ for the analyses of the emotions, credibility, expectancy, motivation, quantity and quality. A Wilcoxon signed rank test (Bonferroni correction, $\alpha=.0167$ ) was conducted for multiple comparison between different test moments (week 1 - week 2 - week $3)$. 


\section{RESULTS}

Subject characteristics are presented in table 2 .

\section{Feasibility}

Adherence

All participants finished the program and completed on average $88.9 \%$ of the sessions. Individual values of training adherence amounted $100 \%$ in two participants, $88.9 \%$ (i.e. $8 / 9$ sessions) in one participant and $77.8 \%$ in two participants (i.e. 7/9 sessions). In the first, second and third week were respectively zero, three and two absences due to a doctor's visit or illness. No significant differences were found in the attendance over time. Even though the active participation during all sessions differed among the participants, the overall participation averaged $84.1 \%$ with individual values varying between $46.1 \%$ and $99.1 \%$.

\section{Quantity Of Performances}

Only the percentage of the repetitions of functional exercises decreased significantly over time $(\mathrm{p}=0.04)$ (figure 1). For all type of exercises, more than $50 \%$ of the repetitions were performed.

\section{Quality Of Performances}

The quality of performances, presented as the percentages of maximum quality are visualized in figure 2. For all type of exercises, a quality of more than $50 \%$ was reached except for static balance exercises in week 1 and for dynamic balance exercises in week 3 .

The quality of performances of the warming-up exercises decreased over time ( $\mathrm{p}=.02)$, the quality significantly decreased in week $2(\mathrm{p}=.04)$ and stabilized in week 3 . No significant differences were found in the quality of performance over time for the other type of exercises.

During the exercise program, the music was not completely adjusted to the video, resulting in a 10 to 15 seconds stop of the music before the end of the warming-up exercises. These situations were accompanied with an early termination of the exercise by the participants. This problem with the music was not present during the other type of exercises.

\section{Motivation}

The median values of all individual scores on the subscales 'interest-enjoyment', 'perceived competence', 'effort-importance', 'perceived choice' were high $(\geq 5 / 7)$, indicating that the participants found the exercise program enjoyable and important to do, without feeling 
obligated to participate (table 3 ). The median values for 'tension-pressure' were low $(<1.5 / 7)$,

\section{Credibility And Expectancy}

Even though the credibility of the participants regarding the program was overall high, the credibility differed significantly over time $(p=0.02)$. The credibility increased $(p=0.04)$ in week 2. Also expectancy of the participants regarding the program differed over time $(\mathrm{p}=0.02)$. The expectancy subscale was low in week $1(<13.5)$ but increased towards week $2(\mathrm{p}=0.04)$ and stabilized in week 3 ( $\mathrm{p}=0.04$ between week 1 and week 3 ) (table 3 ).

\section{Emotions}

The data presented in table 3 reveal that the median score is positive in all subscales: 'alertness', 'anger', 'anxiety', 'sadness', except a negative score in week 2 on the subscale 'pleasure' $(<2.5)$. No significant differences are found over time.

\section{DISCUSSION}

This is the first study demonstrating that a video-based group exercise program accompanied with instrumental music instead of therapeutic instructions is feasible for persons with $\mathrm{AD}$ in nursing homes. Moderate to high adherence was demonstrated and exercises were well tolerated.

The expectations of the participants increased as the program proceeded and the participants believed the exercises could affect their general functioning. Results showed the older adults enjoyed participating the exercise program, they were interested in the program and indicated they endeavored to do their best. Furthermore, they were satisfied with their own performances.

The study illustrated the necessity of music as a motivational stimulus in physical exercises to increase the participation in $\mathrm{AD}[6]$ as participants stopped moving or were less attentive when the music dropped or totally disappeared. Coupling visual information, in this 
case the video, with music could be a supportive component in enhancing the quality of performances [13].

All performances, except the exercises demanding advanced coordination or balance (i.e. exercises in standing position and exercises focused on upper extremities, motor dual tasks or activities with crossing the center line), were of high quality. Therefore, at least one therapist is recommended in order to supervise exercises performed in standing position without external support and to individual correct the performances. However, this form of group therapy with visual (TV-screen) and auditive (instrumental music) stimulation and instructions can increase the efficiency of a physical therapy group session in nursing homes, resulting in more individual time during group exercises.

Some limitations and strengths of the study should be recognized. Only 5 participants were included in this feasibility study. Further, as a result of $\mathrm{AD}$, enthusiasm can differ between and within days, which might have an effect on the quality of each training. To reduce this variable, median values for quality, quantity and emotions were calculated within the same week. This exercise program requires no costly equipment and may therefore be a favorable replacement for many expensive rehabilitation devices. Future research should investigate the added value of the combination of the exercise program with a guiding physical therapist to group therapy solely led by a physical therapist.

Ethical approval: All procedures performed in studies involving human participants were in accordance with the ethical standards of the institutional and/or national research committee and with the 1964 Helsinki declaration and its later amendments or comparable ethical standards. 


\section{REFERENCES}

[1] Scarmeas N, Hadjigeorgiou GM, Papadimitriou A, Dubois B, Sarazin M, Brandt J, Albert M, Marder K, Bell K, Honig LS, Wegesin D, Stern Y (2004) Motor signs during the course of Alzheimer disease. Neurology 63(6): 975-982.

[2] Rao AK, Chou A, Bursley B, Smulofsky J, Jezequel J (2014) Systematic review of the effects of exercise on activities of daily living in people with Alzheimer's disease. Am J Occup Ther 68(1): 50-56.

[3] Cotter VT (2007) The burden of dementia. Am J Manag Care 13(Suppl 8): S193-197.

[4] Ries JD, Hutson J, Maralit LA, Brown MB (2015) Group balance training specifically designed for individuals with Alzheimer disease: Impact on berg balance scale, timed up and go, gait speed, and mini-mental status examination. J Geriatr Phys Ther 38(4): 183-193.

[5] Mehra S, Dadema T, Kröse B, Visser B, Engelbert RH, Van Den Helder J, Weijs PJ (2016) Attitudes of older adults in a group-based exercise program toward a blended intervention; A focus-group study. Front Psychol 7: 1827.

[6] Perilli V, Lancioni GE, Hoogeveen F, Caffó A, Singh N, O'Reilly M, Sigafoos J, Cassano G, Oliva D (2013) Video prompting versus other instruction strategies for persons with Alzheimer's disease. Am J Alzheimers Dis Other Demen 28(4): 393-402.

[7] Mathews RM, Clair AA, Kosloski K (2001) Keeping the beat: use of rhythmic music during exercise activities for the elderly with dementia. Am J Alzheimers Dis Other Demen 16(6): 377-380.

[8] Hutchinson JC, Karageorghis CI, Black JD (2017) The diabetes project: Perceptual, affective and psychophysiological effects of music and music-video in a clinical exercise setting. Can J Diabetes 41(1): 90-6.

[9] Folstein MF, Folstein SE, McHugh PR (1975) Mini-mental state. A practical method for grading the cognitive state of patients for the clinician. J Psychiatr Res 12: 189-198.

[10] Meijer J, van Eck E, Charles Felix SCO-Kohnstamm Instituut van de Universiteit van Amsterdam (2008) Leren met meer effect; rapportage van het onderzoek. http://www.informaticavo.nl/docs/2009/EindrapportageLMME.pdf

[11] Devilly GJ, Borkovec TD (2000) Psychometric properties of the credibility/expectancy questionnaire. J Behav Ther Exp Psychiatry 31(2): 73-86.

[12] Lawton MP, Van Haitsma K, Klapper J (1996) Observed affect in nursing home residents with Alzheimer's disease. J Gerontol B Psychol Sci Soc Sci 51:P3-P14. 
[13] Ghilardi MF, Alberoni M, Rossi M, Franceschi M, Mariani C, Fazio F (2000) Visual feedback has differential effects on reaching movements in Parkinson's and Alzheimer's disease. Brain Res 876(1-2): 112-123. 
Fig. 1 Changes in Quantity (Number of performed Repetitions) over time (Week $1=\square$, Week $2=\square$, Week $3=\square$ ) presented as percentage of maximum score $*=\mathrm{p}<0.05$

Fig. 2 Changes in Quality of performance over time (Week 1= $\square$, Week 2= $\square$, Week 3= $\square$ ) presented as percentage of maximum score

$*=\mathrm{p}<0.05$ 


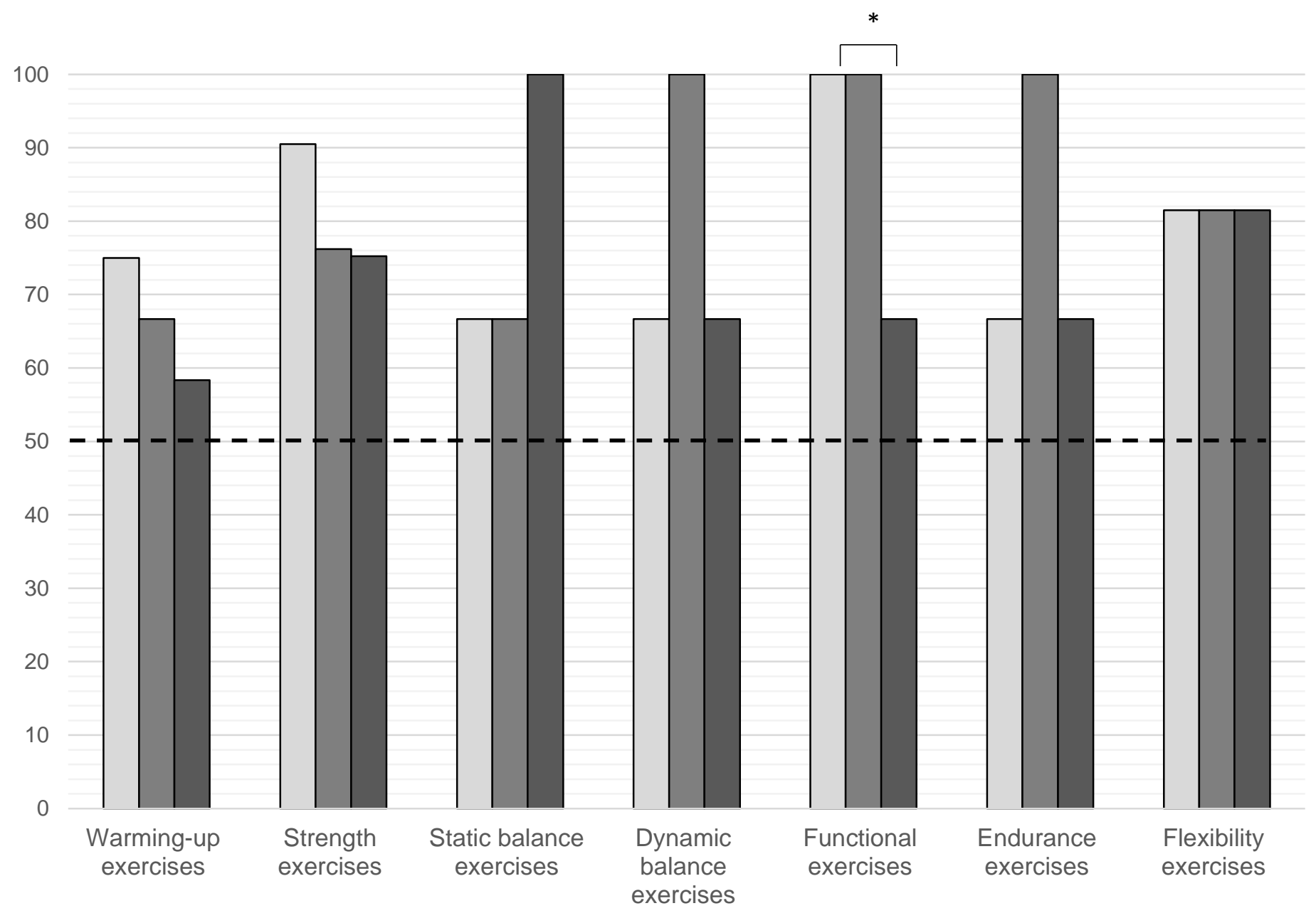


Table 1. Composition of the exercise program over weeks

\begin{tabular}{|c|c|c|c|}
\hline Composition & WEEK 1 & WEEK 2 & WEEK 3 \\
\hline $\begin{array}{l}\text { Warming-up } \\
\text { (5 minutes) }\end{array}$ & $\begin{array}{l}\text { Warming-up exercises } \\
\text { - Ex. 1: marching in sitting position } \\
\text { - Ex. 2: boxing in sitting position } \\
\text { - Ex. 3: lifting knees in standing position } \\
\text { - Ex. 4: clapping hands in standing position }\end{array}$ & $\begin{array}{l}\text { Warming-up exercises (in standing position) } \\
\text { - Ex. 1: alternately bringing legs forward } \\
\text { - Ex. 2: turning arms } \\
\text { - Ex. 3: V-step } \\
\text { - Ex. 4: boxing }\end{array}$ & $\begin{array}{l}\text { Warming-up exercises } \\
\text { - Ex. 1: marching while lifting arms till } 180^{\circ} \\
\text { - Ex. 2: marching sideward and clapping hands } \\
\text { - Ex. 3: marching while making scissor movements with the arms } \\
\text { - Ex. 4: extending legs sideward while extending both arms } 180^{\circ} \\
\text { upwards }\end{array}$ \\
\hline \multirow{5}{*}{$\begin{array}{l}\text { Main } \\
\text { components } \\
\text { (20 minutes) }\end{array}$} & $\begin{array}{l}\text { Strength exercises (in sitting position): } \\
10 \text { repetitions each } \\
\text { - Ex. 1: alternately lifting knees } \\
\text { - Ex. 2: lifting knees and spread legs } \\
\text { - Ex. 3: alternately extending knees } \\
\text { - Ex. 4: feet alternately supporting on tiptoe and heel } \\
\text { - Ex. 5: circular movements with arms spread } \\
\text { - Ex. 6: extending arms forward } \\
\text { - Ex. 7: bending arms with weights }\end{array}$ & $\begin{array}{l}\text { Strength exercises (in standing position): } \\
20 \text { repetitions each } \\
- \text { Ex. 1: lifting legs sideward in standing position with external support } \\
\text { - Ex. 2: lifting legs forward in standing position with external support } \\
\text { - Ex. 3: transfer from sit to stand } \\
- \text { Ex. 4: standing on tiptoes with external support } \\
- \text { Ex. 5: lifting extended arms forward till } 90^{\circ} \text { with weights in standing } \\
\text { position } \\
- \text { Ex. 6: lifting extended arms sideward till } 90^{\circ} \text { with weights in standing } \\
\text { position } \\
- \text { Ex. 7: bending arms with weights in standing position }\end{array}$ & $\begin{array}{l}\text { Strength exercises (with weights): } 30 \text { repetitions each } \\
\text { - Ex. 1: extending knees while alternating bending arms in sitting } \\
\text { position } \\
\text { - Ex. 2: forward and backward rowing in sitting position } \\
\text { - Ex. 3: squat } \\
\text { - Ex. 4: bringing alternately leg sideward while bringing both } \\
\text { extended arms } 90^{\circ} \text { sideward }\end{array}$ \\
\hline & $\begin{array}{l}\text { Static balance exercises (with external support) } \\
\text { - Ex. 1: tandem stand } \\
\text { - Ex. 2: spread stand } \\
\text { - Ex. 3: lifting knees }\end{array}$ & $\begin{array}{l}\text { Static balance exercises } \\
- \text { Ex. 1: unipodal stand with external support } \\
- \text { Ex. 2: tandem stand without external support }\end{array}$ & $\begin{array}{l}\text { Static balance exercises (with reduced external support) } \\
- \text { Ex. 1: standing on tiptoes } \\
\text { - Ex. 2: unipodal stand }\end{array}$ \\
\hline & $\begin{array}{l}\text { Dynamic balance exercise } \\
- \text { Ex. 1: lunges with external support }\end{array}$ & $\begin{array}{l}\text { Dynamic balance exercise } \\
\text { - Ex. 1: lunges without external support }\end{array}$ & $\begin{array}{l}\text { Dynamic balance exercise } \\
- \text { Ex. 1: crossed tapping knees while lifting them }\end{array}$ \\
\hline & $\begin{array}{l}\text { Functional exercise } \\
- \text { Ex. 1: cycle movements in sitting position }\end{array}$ & $\begin{array}{l}\text { Functional exercise } \\
- \text { Ex. 1: lifting knees while marching }\end{array}$ & $\begin{array}{l}\text { Functional exercise } \\
- \text { Ex. 1: lifting knees while marching + combing hair backwards }\end{array}$ \\
\hline & $\begin{array}{l}\text { Endurance exercise ( } 3 \text { minutes) } \\
- \text { Ex. 1: marching with } 3 \text { accelerations ( } 30 \text { seconds) }\end{array}$ & $\begin{array}{l}\text { Endurance exercise ( } 3 \text { minutes) } \\
- \text { Ex. 1: marching with } 3 \text { accelerations ( } 30 \text { seconds) }\end{array}$ & $\begin{array}{l}\text { Endurance exercise ( } 3 \text { minutes) } \\
- \text { Ex. 1: marching with } 3 \text { accelerations ( } 30 \text { seconds) }\end{array}$ \\
\hline $\begin{array}{l}\text { Cooling-down } \\
\text { (5 minutes) }\end{array}$ & $\begin{array}{l}\text { Flexibility exercises (15 seconds each) } \\
\text { - Ex. } 1: \text { neck muscles } \\
\text { - Ex. } 2 \text { : trunk } \\
\text { - Ex. } 3 A+3 B \text { : shoulders } \\
\text { - Ex. } 4 A+3 B \text { : wrists } \\
\text { - Ex. } 5: \text { calf muscles } \\
\text { - Ex. } 6 A+6 B \text { : ankles }\end{array}$ & $\begin{array}{l}\text { Flexibility exercises (15 seconds each) } \\
\text { - Ex. 1: neck muscles } \\
\text { - Ex. 2: trunk } \\
\text { - Ex. } 3 A+3 B \text { : shoulders } \\
\text { - Ex. } 4 A+3 B \text { : wrists } \\
\text { - Ex. } 5: \text { calf muscles } \\
\text { - Ex. } 6 A+6 B \text { : ankles }\end{array}$ & $\begin{array}{l}\text { Flexibility exercises (15 seconds each) } \\
\text { - Ex. 1: neck muscles } \\
\text { - Ex. } 2 \text { : trunk } \\
\text { - Ex. } 3 A+3 B \text { : shoulders } \\
\text { - Ex. } 4 A+3 B \text { : wrists } \\
\text { - Ex. } 5: \text { calf muscles } \\
\text { - Ex. } 6 A+6 B \text { : ankles }\end{array}$ \\
\hline
\end{tabular}


Table 2. Baseline characteristics of the participants presented as Mean (SD) and individual values for each participant $(n=5)$.

\begin{tabular}{|l|c|c|c|c|c|c|}
\cline { 2 - 8 } \multicolumn{1}{c|}{} & Mean (SD) & \multicolumn{5}{c|}{ Individual values } \\
\hline Participant & & P1 & P2 & P3 & P4 & P5 \\
\hline Age, years & $89.6(5.1)$ & 96 & 83 & 88 & 86 & 95 \\
\hline MMSE & $14.2(3.4)$ & 13 & 14 & 20 & 13 & 11 \\
\hline GDS & $2.2(1.6)$ & 4 & 2 & 0 & 4 & 1 \\
\hline Use of walking aids, $\mathbf{n}$ & 4 & 1 & 1 & 0 & 1 & 1 \\
\hline Residential stay, months & $35.1(31.2)$ & 62 & 4 & 3 & 37 & 69 \\
\hline Date of diagnosis, months & $28.6(10.9)$ & 38 & 29 & 17 & 16 & 43 \\
\hline
\end{tabular}

$\mathrm{P} 1, \mathrm{P} 2, \ldots=$ Participant 1, Participant 2,... ; MMSE=Mini-Mental State Examination; GDS= Geriatric Depression Scale 
Table 5. Changes in Intrinsic Motivation Inventory (IMI), Credibility and Expectancy Questionnaire (CEQ) and Observed Emotion Rating Scale (OERS) Scores over Time (Week 1, Week 2, Week 3) presented as Median (IQR).

\begin{tabular}{|c|c|c|c|c|}
\hline Parameters & Week 1 & Week 2 & Week 3 & p-value \\
\hline \multicolumn{5}{|l|}{ IMI } \\
\hline Interest-enjoyment & $5.4(5.4-5.6)$ & $5.6(5.4-5.6)$ & $5.6(5.6-5.7)$ & .68 \\
\hline Perceived competence & $5.5(4.8-5.7)$ & $5(4.7-5.2)$ & $5(4.7-5.5)$ & .68 \\
\hline Effort-importance & $5.8(5.6-5.8)$ & $5.6(5.6-5.8)$ & $5.6(5.2-5.6)$ & .84 \\
\hline Tension-pressure & $1.4(1.2-1.4)$ & $1.2(1.2-1.8)$ & $1.2(1-1.4)$ & .21 \\
\hline Perceived choice & $6.6(6.6-6.6)$ & $6.4(6.3-6.4)$ & $6.6(6.6-6.6)$ & .11 \\
\hline \multicolumn{5}{|l|}{ CEQ } \\
\hline Credibility & $16(15-16)$ & $21(20-22)$ & $17(16-19)$ & $.02^{*}$ \\
\hline Expectancy & $12.4(9.8-13)$ & $15(10.4-16)$ & $15.8(15.8-15.8)$ & $.02^{*}$ \\
\hline \multicolumn{5}{|l|}{ OERS } \\
\hline Pleasure & $3(3-3)$ & $2(2-3)$ & $3(2-3)$ & .31 \\
\hline Anger & $1(1-2)$ & $1(1-1)$ & $1(1-1)$ & .22 \\
\hline Anxiety & $1(1-1)$ & $1(1-1)$ & $1(1-1)$ & .37 \\
\hline Sadness & $1(1-2)$ & $1(1-1)$ & $1(1-1)$ & .22 \\
\hline Alertness & $5(5-5)$ & $5(4-5)$ & $4(3-5)$ & .10 \\
\hline
\end{tabular}

Interquartile range (IQR) presented as (Q1-Q3).

${ }^{*}=p<0.05$ 